\title{
Increasing Number of Children and Poverty: A Multidimensional Approach
}

\author{
Mehmet ZANBAK ${ }^{1} \odot$, Selim ÇAĞATAY ${ }^{2} \odot$
}

\begin{abstract}
This study aims at looking at the effects of increasing number of children on poverty. Unlike monetary approaches based on income and consumption expenditures, the multidimensional poverty approach, which includes dimensions such as education, health and environmental factors, can conduct a more accurate analysis based on the deprivation of individuals and households. In other words, determining how a differentiation in household size based on the number of children is reflected in the multidimensional poverty of the household is among the main goals of the study. For this purpose, in light of the data of the head of households based on the 2006 and 2017 data of the Turkish Statistical Institute (TurkStat), a multidimensional poverty measurement is carried out for Nomenclature of Territorial Units for Statistics (NUTS) Level-1 regions of Turkey and for the entire country and it is examined whether the increase in the number of children might cause an increase in the household poverty. It can be specified among the findings of the study that the multidimensional poverty is increased with the increased number of children in the households as we move from west to east of Turkey.
\end{abstract}

Keywords: Number of children, Household size, Multidimensional poverty.

JEL Codes: I32, O18, R29.

\section{INTRODUCTION}

The increase in the average number of children in households has been voiced for nearly two decades and is even supported by some policies. The short-term and long-term effects of the increasing number of children in the household may differ and may have different effects on the welfare level of these households. For example, whether children who reach the age of 15 will be employed or continue their education in the labour market depends on the economic conditions and capabilities of the households. If they are employed, what kind of jobs they are going to get, how much added value will be produced; if they continue education, what quality and what kind of education they will receive are all important questions to be answered and planned in advance. Of course, it is another possibility to enter the labour market but stay unemployed. Data published by TurkStat (2020) indicate that the unemployment rate for $15-24$ age group is $26.1 \%$. Besides, the rate of those who are neither in education nor in employment is around $29.3 \%$. When these two rates are evaluated together, it can be said that a significant portion the youth are not in a position to bring income to their households. Therefore, increase in number of children without the improvements to the current economic conditions in Turkey would be negatively reflected on the poverty of households in the coming period. Based on this perspective, this study aims at looking at the relationship between increasing number of children and poverty.

In the literature poverty is often considered as the monetary deprivation. However, in cases where there is sufficient income, there may be different types of deprivations in households regardless of income level. Different deprivations lead to a poor quality of life for individuals and households, and even their freedom can be restricted. In this case, looking at and measuring the phenomenon of poverty only in monetary terms may mean ignoring the various dimensions of the problem. The first studies on the lack of this diagnosis and measurement method entered the literature within the framework of the Sen (1976)'s "capabilities approach".

1 mehmetzanbak@akdeniz.edu.tr

2 selimcagatay@akdeniz.edu.tr 
Later, Alkire and Foster (2011a; 2011b) introduced the multidimensional poverty method to the literature and in parallel with this, created a measurement method that takes all dimensions into account.

In this study, Alkire et al. (2014)'s multidimensional poverty measurement method -referred as the Alkire-Foster (AF) method in the literature- is used to highlight the forgotten and lost dimensions of poverty and the dimensions, indicators and weights used in calculations are chosen accordingly with Alkire and Foster's suggestions. Special attention is given to health and education indicators of households in calculations as access to education and health opportunities has an important place among the basic capabilities of the individual. While these two basic variables, which are also included in the United Nations Sustainable Development Goals, contribute to the increase in the quality of life of the individual, the deficiencies in these skills stand out as an indicator of underdevelopment. For this reason, in this study, education and health indicators represent 5 of the 12 indicators focused on in the measurement of poverty.

Accordingly, it was deemed appropriate to make an assessment for the whole Turkey and then 12 NUTS Level-1 regions according to the Nomenclature of Units for Territorial Statistics (NUTS) in the first place to the extent permitted by the data set. In the study, the sample group was also separated according to the number of children in order to highlight the effects of the diversity in the number of children on poverty. For this purpose, the data of household heads of households with a mother and father and at least 1 child were used and single-parent households with or without children were not included in the study.

In this study, it is planned to get answers to the following questions; how the multidimensional poverty of the households change when the number of children increases up to 3 and more rather than a single child per household, whether the household poverty differentiates from west to the east of the country as the number of children increases, and lastly, how multidimensional poverty occurred on a national and regional basis between 2006-2017. For this purpose, the second part of the study introduces the multidimensional approach and measurement method, and the empirical literature using this methodology is given in part three. In the fourth part, in light of the data discussed, findings regarding national and regional multidimensional poverty are presented. Last part concludes with a general evaluation.

\section{MULTIDIMENSIONAL MEASUREMENT OF POVERTY WITH THE ALKIRE-FOSTER METHOD}

The Alkire-Foster Method (Alkire and Foster, 2011a; 2011b) (shortly AF Method) was developed by Sabina Alkire and James Foster. The FGT index (Foster et al., 1984 ) is a poverty measurement method used by Foster-Greer-Thorbecke and forms the basis of the Alkire-Foster Method together with the "capability approach" of Amartya Sen (1976). The Alkire-Foster Method, which was introduced to the literature in 2011, has since become a measurement method that is frequently used in many of the research on multidimensional poverty. When measuring poverty, the main problem is determining the thresholds of deprivation and poverty of the individual. These thresholds must be correctly analysed in order to identify the individual as poor or not. In the Alkire-Foster method, measurements are made on a counting basis. In this method, the "dual cutoff" approach is used as a method of determining the depth of poverty, even its severity and even intensity within the group by dividing poverty into subgroups, where the thresholds of deprivation and poverty can be determined effectively.

In order to develop a design that accepts the approach based on the Alkire-Foster Method as the fundamental dynamic and which is a "multidimensional poverty index (MPI)" based on observation, it is necessary to determine many and different parameters in a healthy and accurate manner. In the selection of these parameters, which will be used while designing the multidimensional poverty index, the data is passed through some stages. These stages can be listed under five headings as follows (Alkire, 2018; Alkire et al., 2014; Song and Imai, 2018):

Dimensions: The first and most important step is the dimension selection to make an accurate measurement. While selecting the dimensions, it should be made in a way that gives the healthiest results for the sample group. Dimensions should cover everyone in the sample, and no observations made in the sample should be ruled out. (Alkire and Jahan, 2018).

Indicators: Indicators are the elements that clearly demonstrate the situation of the sample group, which are developed to expose the deprivation of individuals or households in social, economic or cultural areas.

Deprivation Cutoffs: Accurate measurement of the index is possible with the correct determination of deprivation cutoffs. Deprivation cutoffs are the deter- 
mination of a minimum level of capability determined as a result of determining whether an individual or household can be considered deprived for each indicator to be measured.

Weighting: Relative weighting determines how much the dimension and sub-indicators selected will affect the index. Selection of weighting is done entirely by the author. The effect ratios of these dimensions and sub-indicators selected by the author are equal in general. However, there are alternative weighting methods according to the sample group to be observed and inferred (Seth and McGillivray, 2018).

Poverty Cutoffs: The author of the research should have comprehensive information about the sample in order to determine poverty cutoffs correctly. This is because this threshold is generally set in line with the expectations of the researcher (Alkire and Foster, 2011 b). Poverty cutoffs are the lowest limit values calculated by weighting from each indicator in order to identify the individual or household as poor according to the study to be conducted.

Following the steps listed above, the dimensions, indicators, deprivation cutoffs, weighting and poverty cutoffs are determined in accordance with the Alkire-Foster approach. In light of all this data, the next step is to create achievement matrices using the data obtained from the household through the survey. Thus, the deprivation matrix indicating which individual in the sample is deprived of in what dimension/indicator is reached. In this process leading to the deprivation matrix, individual deprivations in dimensions/indicators should be determined first. For the data obtained as a result of this determination, it can be said that the AF method measures poverty by using the matrices. Since the Alkire-Foster method is counting-based, first the matrices are defined, then multidimensional poverty and related multidimensional poverty indices are calculated using the censored matrix (Alkire and Foster, 2011b). It is possible to express the steps taken in a mathematical plane;

First, the $Y=\left[y_{i j}\right]_{n \times d}$ matrix, which is created and called the achievement matrix consisting of $n$ observations (individuals) and $d$ dimensions/indicators $(n x d)$ with raw data, is defined. In this $[y]_{n \times d}$ matrix, the columns represent dimensions and sub-indicators of dimensions, if there are any. Each row gives the values that each individual in the sample receives in dimensions/ indicators ( $i=1, \ldots, n$ and $j=1, \ldots, d)$. For example, the point where the first row and first column intersect (the value expressed as $y_{11}$ in equation 1) shows the value of the first individual in the first dimension/indicator.

\section{Dimension}

$$
Y=\left[\begin{array}{ccccc}
y_{11} & y_{12} & y_{13} & \ldots & y_{1 d} \\
y_{21} & y_{22} & y_{23} & \ldots & y_{2 d} \\
y_{31} & y_{32} & a_{33} & \ldots & y_{3 d} \\
y_{41} & y_{42} & y_{43} & \ldots & y_{4 d} \\
\ldots & \ldots & \ldots & \ldots & \ldots \\
y_{n 1} & y_{n 2} & y_{n 3} & \ldots & y_{n d}
\end{array}\right] \text { Individual }
$$

In the second step, the "deprivation cutoff" vector matrix is defined.

$$
Z=\left[\begin{array}{lllll}
Z_{11} & Z_{12} & Z_{13} & \ldots & Z_{1 d}
\end{array}\right]
$$

It is a $1 x d$ matrix shown in Equation 2 and the value belonging to each dimension determined by the researcher is compared with the threshold values of the dimension to which it belongs. Individuals below or above these values are considered to be deprived of that dimension depending on the character of the dimension. The mentioned-matrix is important in revealing which individual is deprived of which dimension.

In the third step, the deprivation counts matrix is defined.

$$
\mathrm{C}=\left[\begin{array}{lllll}
\mathrm{C}_{11} & \mathrm{C}_{21} & \mathrm{C}_{31} & \ldots & \mathrm{C}_{\mathrm{n} 1}
\end{array}\right]^{\prime}
$$

It is a $n \times 1$ matrix shown in Equation 3 (transposition of the equation). The dimensions that each individual is deprived of are counted, these dimensions are added together and the sum is written into this matrix. In this way, the dimensions the $\mathrm{n}^{\text {th }}$ individual is deprived of are revealed. This is an important indicator in terms of reflecting the depth of an individual's deprivation (Alkire and Foster, 2011a; 2011b).

In the fourth step, the poverty cutoff value is defined. This value, which is expressed as $k$, must be greater than zero and smaller than the total number of dimensions used in the study $(0<k<d)$. In the AF method, it is generally taken as $2(k=2)$. If the mentioned $k$ value compared with the values in the $C$ matrix in the equation 3 , which shows the total deprivation count mentioned in the third step, is found to be smaller than the value in each row of the $C$ matrix, the individual in that row is considered poor. This is a very important value in terms of showing how many people are under the $k$ cutoff value and how many poor individuals there are in this observation group; thus, it should be 
selected very carefully. Otherwise, if the cutoff value of $k$ is taken higher than it should be, the number of poor in the observation group will be lower than expected, or on the contrary, the majority of the observation group will be above the poverty line. In such a case, the measurement will not give accurate results and accurate policies will not be developed. These four steps mentioned are explaining how the definitions should be for a measurement carried out with the AF method. The steps should be followed for the measurement are shown in Figure 1.

\section{Calculation of the multidimensional poverty index $\left(M_{0}\right)$ :}

Headcount ratio $(H)$ : This concept, which is frequently used in poverty measurements, is called by various names such as the poverty rate, ratio of the number of people. In other words, while $q$ represents the number of poor individuals in the total population, $n$ represents the total population, the headcount rate $H$ is calculated as shown in equation 4 .

$$
H=\frac{q}{n}
$$

This ratio, calculated using equation 4 , takes a value between 0 and 1 , which indicates that if the ratio is 0 , there is no poor person in the population, and if it takes the value 1, the whole population is poor (Haughton and Khandker, 2009).

Average deprivation ratio $(A)$ : This ratio is very important in terms of showing the depth of poverty and showing the deprivation that poor people experience per dimension. The sum of deprivations; represents the sum of the total deprivation counts each individual is exposed to, $q$ represents the number of poor individuals in the total population mentioned in the headcount rate, $d$ represents the total number of dimensions in the achievement matrix in equation 1 , while the average

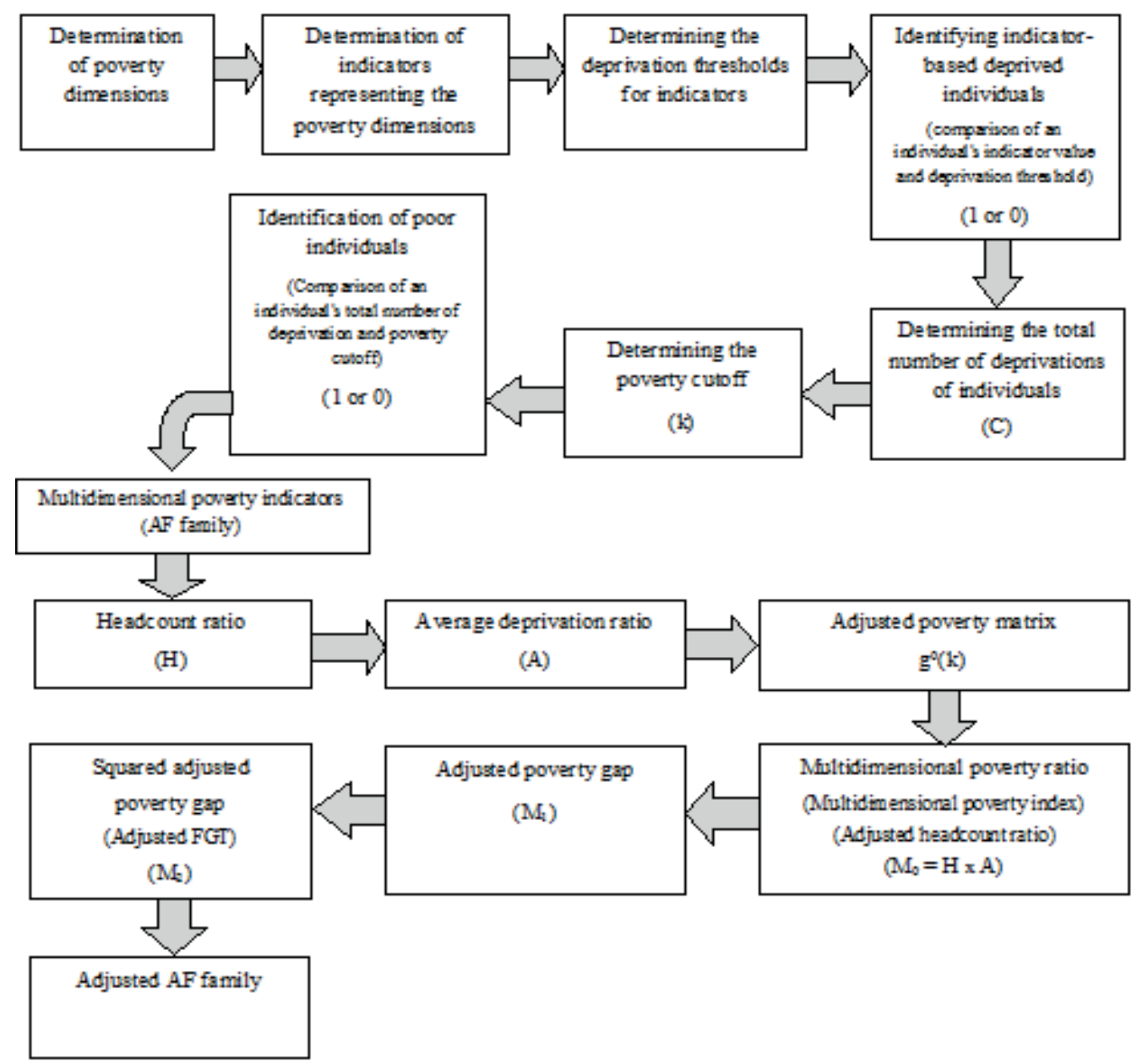

Figure 1: The Stages of Multidimensional Poverty Measurement

Source: Zanbak and Çağatay, 2013. 
deprivation ratio is calculated as shown in equation 5 (Zanbak, 2014).

$$
A=\frac{\text { Average Deprivation }}{\text { Number of Dimensions }}=\frac{\frac{\text { Sum of Deprivations }}{\text { Number of Poor Individuals }}}{\text { Number of Dimensions }}=\frac{\frac{\sum_{1}^{d} c}{q}}{d}
$$

Adjusted headcount ratio (multidimensional poverty index) $\left(M_{0}\right)$ : The adjusted head count ratio is the most commonly used index in the Alkire-Foster method and it is very important in terms of showing the level of poverty experienced. This importance is due to the fact that it allows the factors such as units, regions, etc. affecting the poverty index to be revealed by dividing the observation group into subgroups and the index can be subdivided into subgroups. $M_{0}$ can be calculated in two different ways: In the first way, this ratio is obtained by multiplying the headcount ratio $(\mathrm{H})$ and the average deprivation ratio $(A)$ as given in equation 6 . In the second way, it is calculated by taking the arithmetic average (: arithmetic average function) of " $g$ ( $k)$, censored deprivation matrix" shown in equation 7 (Alkire and Foster, 2011b).

$$
\begin{aligned}
& M_{0}=H x A \\
& M_{0}=\mu\left[g^{0}(k)\right]
\end{aligned}
$$

\section{LITERATURE REVIEW}

In this section, the empirical literature will be evaluated from two different angles, and in the first stage, studies conducted using a multidimensional approach, which is a method of addressing poverty, will be included. Some of the research looking at the relationship between household size and poverty based on the number of children will be summarized in the following sections.

In order to overcome the lack of monetary poverty measurements both in the national and international arenas, new ways have been proposed, and poverty has been attempted to be disclosed by evaluating all aspects of life with these approaches. Sen (1976; 1983; 1997; 1999; 2004) and Foster et al. (1984) can be listed among the first researchers to distinguish these approaches from monetary methods. These studies, in contrast to the narrow view of poverty in the discipline of economics, emphasize that poverty is not solely dependent on income, and that everything related to a good life should be taken into account in the measurement of poverty. One of the first and most important studies to introduce a distinct perspective to poverty measurements was conducted by Bourguignon and
Chakravarty (2003). A multidimensional computation method is offered in the study as an alternative to monetary approaches, with each dimension having its own poverty line. It is suggested that the poverty dimensions should be defined first, followed by the poverty lines of these dimensions.

Alkire and Foster's (2011a) study includes another measurement method that differs from monetary approaches and takes its place as the "AF Approach" in the literature. While this approach differs from monetary approaches with more than one dimension in the analysis, it also differs from the multidimensional approaches developed in previous years by calculating the average deprivation rate, the average poverty gap, the square of the average poverty gap representing the severity of the gap, and thus obtaining the adjusted headcount ratio, the adjusted poverty gap and the adjusted FGT (squared adjusted poverty gap). In their study of poverty measurement theory, Lugo and Maasoumi (2009) aimed to introduce the poverty rates calculated using monetary indicators and the rates calculated using a multidimensional approach, and analyzed poverty among three ethnic groups in Indonesia in terms of expenditure, health status and education level. One of the most comprehensive worldwide studies of multidimensional poverty measurement is the study of Alkire and Santos (2010), which covered 104 developing countries and used data from 2000 to 2008 . A poverty calculation based on income was also made in the study, and it was determined whether they were poor using a multidimensional approach. Alkire and Foster (2011b), who conducted one of the pioneering studies in measuring poverty in a multidimensional way, noted that it is insufficient to reflect poverty only with monetary indicators, and therefore, the missing dimensions of poverty should be included in the calculation. It has also been stated that determining the indicators that would represent these missing dimensions, which also contribute to a better understanding of poverty, and the determination of their deprivation lines is a difficulty. According to the researchers, the most significant contribution of the AF approach to the literature, which determines poor individuals based on the number of deprivations they have experienced, is that the average deprivation experienced by the individual is included in the measurement, and the adjusted headcount ratio is calculated in this way.

The human development index and income-based poverty rates were calculated first in the study of Batana (2013), one of the studies that analyzes 
poverty multidimensionally in 21 Sub-Saharan African nations, and then the values obtained were compared with multidimensional poverty rates based on the AF approach. Assets, health, education, and empowerment dimensions (11 indicators) were included in the calculation to make the study multidimensional, while the poorest sub-regions and the dimensions with the highest deprivation were also analyzed.

Another study group that will be covered under the title of literature consists of studies that look at how poverty evolves as household numbers differ. Anand's (1977) study uses field research data to evaluate the scope and nature of poverty in Malaysia. The findings reveal that the relationship between household size and poverty in Malaysia is positive up to 7-member households, and the relationship thereafter is uncertain. Furthermore, when the percentage distribution of household size between poor and non-poor households was compared, it was discovered that the impoverished have a larger average household size. In another study within this scope, Anyanwu (2005) used a logistic regression model to assess the profile of rural poverty in Nigeria using the 1996 national consumer survey dataset. According to the findings, there is a positive and substantial relationship between household size and the likelihood of being impoverished in Nigeria's rural areas. Similarly, Anyanwu (2014) looked at the effect of household size and marital status on poverty in Nigeria, using data from the 2009/2010 Harmonized Nigerian Standard of Living Survey. The findings show that household size has a considerable effect on poverty. While poverty was found to be lower in single-person households, it was discovered that the likelihood of being poor increased as the number of children in the household increased.

Geda et al. (2001) conducted another study focusing on the relationship between household size and poverty. The researchers used binomial and multidimensional logit models to examine the possible drivers of Kenya's poverty condition in the light of household-level data gathered in 1994. As a result of the findings, it has been shown that household size has a positive and strong relationship with poverty. Khan et al. (2015), on the other hand, used data from a rural-based household survey to examine the determinants affecting poverty in 600 families in Pakistan's Bahawalpur region, and found that household size considerably increased household poverty as a result of the estimation.
Furthermore, in their study evaluating the poverty patterns of extended families in developing nations, Lanjouw and Ravallion (1995) used the data of a field study conducted with 4,794 households in urban and rural parts of Pakistan in 1991. As a result of the analysis, a positive correlation was found between poverty and household size for Pakistan, indicating that the increase in the number of people in the household also increased poverty. Meyer and Niyimbanira (2016) employed Pearson's chi-square test method to examine the relationship between household size and poverty in low-income communities, using data from 12 communities (about 2900 families) in the Northern Free State region of South Africa. According to the findings, a positive relationship was found between household size and poverty in 11 of 12 communities.

\section{THE EFFECT OF THE HOUSEHOLD POPULATION WHICH DIVERSIFIES ACCORDING TO THE NUMBER OF CHILDREN ON MULTIDIMENSIONAL POVERTY}

\subsection{Sample}

In this study, the required data was obtained by extracting the cross-sectional data of the Turkish Statistical Institute Income and Living Conditions Survey in 2006 and 2017. When the raw data are analysed for the sample group of 2006, it is observed that there were 10,920 households in the country and a total of 30,186 people live in these households. Accordingly, it can be said that the average population was about 3 (2.7) per household in 2006. Similarly, when the sample group for 2017 is examined, it is seen that there are 22,869 households and 58,744 individuals living in these households and the average household size is 2.5 .

Since the main purpose of this study is to determine how the size of households that differ according to the number of children is reflected in poverty, the relevant sample is also divided according to the number of children. In this respect, in the first stage, the sample was grouped into households with one, two to three and more children with a precondition of including households with married individuals in the analysis. As shown in Table 1, the number of households with one child is 1366, 1652 with two children, and 1398 with three or more children for the year of 2006. On the other hand, the number of households with one child is 2907, 3237 with two children, and 2203 with three or more children for 2017. 
Another aim of the study is to determine how the household poverty, which differs with the change in the number of children, is distributed by regions. For this purpose, the data of twelve NUTS Level-1 regions were used. Hence, when the households of both 2006 and 2017 are analysed from a regional perspective, the number of children is increasing from west to east. It can be said that the number of households with three or more children, especially in the regions of Northeast Anatolia, Middle Eastern Anatolia and Southeastern Anatolia, stood out in both 2006 and 2017. On the other hand, it can be emphasized that the number of households with two children is higher than the others for both analysis years towards the west.

Before the multidimensional poverty measurement of the households shown in Table 1, which differed by the number of children and years, comparing the average incomes of the regions with the average income of Turkey, it can be said that some regions have diverged from the overall average in a positive and some in a negative way. While the average income of households with 1 child in the western regions of the country is above the country average, this situation reverses as the number of children increases in the eastern regions. For example, even though the average income of a household with one child for Istanbul Region in 2006 was 1.3 times the average income of Turkey, the average income of the region in 2017 has come to the same level as the national average. This region is one of the most advantageous regions in terms of average income, and this result can be seen as normal considering the potential for the labor market.
As mentioned, the increase in the number of children and the orientation to the eastern regions resulted in a lower household income than the national average, but this situation did not differ significantly between 2006 and 2017. In other words, the ratio of the average income of households with three or more children in regions other than Istanbul and East Marmara regions to the national average is not very different from each other on the basis of both years. In addition, the regions with an average income of households with three children below the average income of Turkey can be listed as Southeastern Anatolia, Middle Eastern Anatolia and Eastern Black. At this point, it can be emphasized that the same regions showed a slight improvement from 2006 to 2017 and converged to the country average at a low rate.

\subsection{Dimensions, Indicators, Deprivation Conditions, and Weights Used in the Study}

In order to calculate the poverty of households and to determine which indicators stand out as the number of children differs, "Europe 2020; A Strategy for Smart, Sustainable and Inclusive Growth" (European Commission, 2010) was taken as the basis and the dimensions, indicators and weights specified in the study of Alkire et al. (2014) were used'. Alkire et al. (2014) created a set of indicators in which Europe 2020, education, health and environmental factors are evaluated together for poverty measurement. The weighting method varying according to the number of dimensions was selected in this formation, which includes a total of four dimensions and twelve indicators representing these dimensions.

Table 1: Regional Distribution of Households Varying by the Number of Children.

\begin{tabular}{|c|c|c|c|c|c|c|c|c|c|c|c|c|c|c|}
\hline \multirow[t]{2}{*}{ TR1 } & & $\begin{array}{l}\text { Istan- } \\
\text { bul }\end{array}$ & $\begin{array}{l}\text { West } \\
\text { Mar- } \\
\text { mara }\end{array}$ & $\begin{array}{l}\text { Aege- } \\
\text { an }\end{array}$ & $\begin{array}{l}\text { East- } \\
\text { ern } \\
\text { Mar- } \\
\text { mara }\end{array}$ & $\begin{array}{l}\text { West- } \\
\text { ern } \\
\text { Ana- } \\
\text { tolia }\end{array}$ & $\begin{array}{l}\text { Medi- } \\
\text { terra- } \\
\text { nean }\end{array}$ & $\begin{array}{l}\text { Cen- } \\
\text { tral } \\
\text { Ana- } \\
\text { tolia }\end{array}$ & $\begin{array}{l}\text { West- } \\
\text { ern } \\
\text { Black } \\
\text { Sea }\end{array}$ & $\begin{array}{l}\text { East- } \\
\text { ern } \\
\text { Black } \\
\text { Sea }\end{array}$ & $\begin{array}{l}\text { North- } \\
\text { east } \\
\text { Ana- } \\
\text { tolia }\end{array}$ & $\begin{array}{l}\text { Mid- } \\
\text { dle } \\
\text { East- } \\
\text { ern } \\
\text { Ana- } \\
\text { tolia }\end{array}$ & $\begin{array}{l}\text { South- } \\
\text { east- } \\
\text { ern } \\
\text { Ana- } \\
\text { tolia }\end{array}$ & Turkey \\
\hline & & TR2 & TR3 & TR4 & TR5 & TR6 & TR7 & TR8 & TR9 & TRA & TRB & TRC & TR & \\
\hline \multirow{2}{*}{1 child } & 2006 & 200 & 131 & 228 & 135 & 121 & 172 & 83 & 77 & 68 & 49 & 45 & 57 & 1366 \\
\hline & 2017 & 323 & 225 & 432 & 339 & 300 & 355 & 163 & 245 & 92 & 124 & 115 & 194 & 2907 \\
\hline \multirow{2}{*}{2 children } & 2006 & 208 & 138 & 228 & 142 & 176 & 199 & 104 & 114 & 99 & 75 & 77 & 92 & 1652 \\
\hline & 2017 & 331 & 186 & 440 & 333 & 332 & 427 & 254 & 271 & 98 & 155 & 187 & 223 & 3237 \\
\hline \multirow{2}{*}{$\begin{array}{l}3 \text { children } \\
\text { and } \\
\text { above }\end{array}$} & 2006 & 108 & 35 & 68 & 57 & 94 & 150 & 102 & 74 & 66 & 152 & 163 & 329 & 1398 \\
\hline & 2017 & 165 & 44 & 121 & 137 & 166 & 285 & 150 & 98 & 53 & 172 & 264 & 548 & 2203 \\
\hline
\end{tabular}


At this point, the dimensions and indicators included in the analysis can be introduced. The Europe 2020 dimension, the first of these four dimensions, includes "income", "work intensity" and "extreme material deprivation" sub-indicators. The income deprivation of the individual and therefore the household is determined by comparing whether the equivalent per capita income determined using the OECD scale is below $60 \%$ of the median income. In this study, which investigates household poverty rather than individual poverty, the household head data determined by verbal statements were used to include income and other indicators in the study. Another indicator that reflects the income dimension is extreme material deprivation, in which the Eurostat norms are taken as the basis in the determination of deprivation. According to Eurostat, in order to be able to say that an individual is experiencing extreme material deprivation, at least four of the following nine items should be experienced at the same time; inability to afford unexpected expenses; difficulty in paying debts such as rent, bills, mortgage loan etc.; inability to meet the heating needs of the house; not being able to eat meat, chicken or fish every other day; inability to take a one-week vacation with all family members away from home; not being able to own a washing machine, colour television, mobile phone and car. In addition, in determining the work intensity representing the Europe 2020 dimension, the ratio of the total number of months worked by individuals of working age to the number of months they are eligible to work becomes important, and individuals with this ratio below 0.2 are considered deprived. As mentioned, in determining the dimensions and indicators used in the study, the study of Alkire et al. (2014) was taken as the basis and the researchers attached importance to the education dimension in order to obtain the multidimensional poverty index. In fact, this dimension was represented by a single indicator in the form of basic education by taking its potential impact on other dimensions into consideration. In other words, due to the high power of influencing both income and indicators in other dimensions, the weight of the indicator representing education has become relatively prominent. The fact that the individual has not received primary education corresponds to the deprivation in the education dimension.

Another dimension used in the calculation of the multidimensional poverty index is related to health. There are four sub-indicators under this dimension. A determination that is defined as bad or very bad in the health status indicator of the individual leads to the acceptance of the individual as deprived in this indicator. The second sub-indicator in the health dimension focuses on whether the individual has a chronic disease or not, and the presence of the individual's chronic disease indicates deprivation. In the third indicator of the health dimension, which focuses on whether there is a limitation in the activities of the individual (eating, sports, etc.) due to health problems, the person is considered to be deprived if he/she feels physically inadequate. In addition, the final indicator of health points out the capacity of the individual to consult a doctor in case of need. If the person is unable to apply to a doctor or any health institution due to severe health problems, this person is considered deprived in this indicator. Another indicator group considered by Alkire et al. (2014) while calculating the multidimensional poverty index includes environmental factors. In the first environmental factor indicator focusing on the environment in which the individual lives and the physical structure of the house, if the roof of the house where the individual lives is leaking water, the walls are damp and the window profiles are rotten, the person is considered deprived. Another of the four environmental factor indicators focuses on noise pollution. If the household is exposed to disturbing sounds from neighbours or the street, the individuals in this household are included in the analysis as deprived. Furthermore, if there is industrial-based air pollution, traffic density, environmental degradation and pollution in the environment where the individual lives, he/ she is considered to be deprived in this indicator. The final indicator points to the possibility of an individual facing criminal incidents, and the fact that the crime is hosted or violent incidents are encountered in the living environment makes the individual deprived.

At this point, the dimensions, indicators and indicator weights used in the calculation of multidimensional poverty can be shown as in Table 2 .

Alkire et al. (2014) put different options in the weighting of indicators when measuring, specifying the number of indicators in the health dimension as three, then four, and included the indicator weights of this dimension as $1 / 12$ and $1 / 16$, respectively. In this study, in which the reflection of the household population that differs by the number of children to multidimensional poverty is tested, the health dimension is represented by four indicators, as emphasized above, so the weight of each indicator of the health dimension included in the measurement is $1 / 16$. The weight of the indicators of the Europe 2020 dimension, which includes three 
indicators, is $1 / 12$, the weight of the indicator for the education dimension, which includes only one indicator, is $1 / 4$, and lastly, the weight of the indicators in the environmental factors dimension where the four indicators are included in the analysis is $1 / 16$.

After determining the dimensions, indicators, deprivation conditions and weights required for measurement, it has become possible to calculate multidimensional poverty on a national and regional scale (Level-1). Therefore, the multidimensional poverty index measurement phase was started after these determinations. Following the creation of the required matrices of the 2006 and 2017 sample groups, which differed according to the number of children, the Headcount Ratio $(\mathrm{H})$ and the Average Deprivation Ratio $(A)$ were calculated in the first place, and then the Multidimensional Poverty Index $\left(M_{0}\right)$ consisting of these two ratios was obtained. In other words, the multidimensional poverty of households with one, two, three or more children aged 15 and under was calculated both nationally and regionally and policy recommendations were presented in the light of the findings.

\subsection{Multidimensional Poverty of Households Differentiated by Number of Children in Turkey}

Once the necessary matrices were created, the poverty cutoff was set to $k=26 \%$ in order to calculate the poverty of the sample group, which was also separated according to regions. In other words, if the value of each row of the matrix showing the sum of the deprivation counts $(C)$ is 0.26 and above, it can be said that the households ${ }^{2}$ in that row are considered deprived. When the share of deprivations in the regions under the indicators and conditions of poverty is examined throughout Turkey, it is observed that Istanbul stands out with single-child households, while the Southeastern Anatolia Region stands out with households with 3 or more children. In other words, while $15 \%$ of the nationwide deprivation in 2006 was experienced in the Istanbul region, this share was realized as 11\% in 2017. The shares of deprivation experienced by households with 3 or more children in the same region in 2006 and 2017 were $8 \%$ and $7.5 \%$, respectively. However, it can be emphasized that the deprivation in households with one child is concentrated in the western regions, while it is concentrated in households with three or more children in the eastern regions. In particular, the

Table 2: Dimensions, Indicators, and Weights Used in the Multidimensional Poverty Measurement.

\begin{tabular}{|c|c|c|c|}
\hline Dimensions & Indicators & Deprivation Conditions & Weights \\
\hline \multirow{3}{*}{ Europe 2020} & Income & $\begin{array}{l}\text { If the equivalent per capita income is below } 60 \% \text { of the } \\
\text { median income }\end{array}$ & $1 / 12$ \\
\hline & $\begin{array}{l}\text { Extreme Material } \\
\text { Deprivation }\end{array}$ & $\begin{array}{l}\text { If deprived from at least four of the nine items determined } \\
\text { by Eurostat }\end{array}$ & $1 / 12$ \\
\hline & Work Intensity & $\begin{array}{l}\text { If the ratio of the total number of months worked by } \\
\text { individuals of working age to the number of months, they } \\
\text { are eligible to work is below } 0.2\end{array}$ & $1 / 12$ \\
\hline Education & Graduated School & If the person didn't receive primary school education & $1 / 4$ \\
\hline \multirow{4}{*}{ Health } & Health Status & $\begin{array}{l}\text { If the individual describes his/her health status as bad or } \\
\text { very bad }\end{array}$ & $1 / 16$ \\
\hline & Chronic Health Problem & If the person has a chronic disease & $1 / 16$ \\
\hline & Limitation in the Activities & If the individual has difficulty performing daytime activities & $1 / 16$ \\
\hline & $\begin{array}{l}\text { Being Unable to Apply to } \\
\text { the Doctor }\end{array}$ & $\begin{array}{l}\text { If the individual is unable to apply for a medical } \\
\text { examination and doctor in case of need }\end{array}$ & $1 / 16$ \\
\hline \multirow{4}{*}{$\begin{array}{l}\text { Environmental } \\
\text { Factors }\end{array}$} & Housing & $\begin{array}{l}\text { If the roof of the household where the individual lives is } \\
\text { leaking, the wall is damp, the window is rotten }\end{array}$ & $1 / 16$ \\
\hline & Noise Pollution & $\begin{array}{l}\text { If the household of the individual is disturbed by the } \\
\text { sounds coming from the street or from the neighbours }\end{array}$ & $1 / 16$ \\
\hline & Environmental pollution & $\begin{array}{l}\text { If there is a traffic problem, industry-induced air pollution } \\
\text { and environmental pollution in the environment where } \\
\text { the individual lives }\end{array}$ & $1 / 16$ \\
\hline & Crime & $\begin{array}{l}\text { If the individual is intensely faced with crime and violence } \\
\text { problems in the environment where he/she lives }\end{array}$ & $1 / 16$ \\
\hline
\end{tabular}


Eastern Anatolia Region contains an important part of the total deprivation experienced in this sample group. In other words, while $13 \%$ of households with 3 or more children and experiencing deprivation in at least one of the indicators were located in Southeastern Anatolia in 2006 , this ratio reached $20 \%$ in 2017 . In other words, 1 out of every 5 individuals, who is deprived of at least one indicator in the mentioned sample group, lives in Southeastern Anatolia. Other regions where deprivation proportionately stands out in at least one indicator in both time periods in households with 3 or more children, which can also be defined as crowded households, are the Mediterranean, Central Anatolia and Middle Eastern Anatolia Regions. However, in this sample group, the proportion of those in the same situation in Western Marmara is $2.7 \%$ and $2.3 \%$, respectively.

After determining the deprivations at the point reached, the headcount ratio $(\mathrm{H})$, average deprivation ratio (A) and multidimensional poverty index $\left(M_{0}\right)$, obtained by multiplying these two values, were calculated for Turkey and then Level- 1 regions (Figure 2 and Figure 3 ).

First, as shown in Figure 2 and Figure 3, the findings related to multidimensional poverty ratios in 12 regions of Turkey for the years 2006-2017 can be evaluated. However, at this point, it is useful to give preliminary information about how these graphics should be interpreted and what the different colours represent. In both Figure 2 and Figure 3, the blue bar represents the multidimensional poverty ratios of households with 1 child, the red bar with 2 children, and the green bar with 3 or more children, respectively. The relatively long length of a bar with the same colour indicates that poverty in that region is relatively high compared to other regions. Furthermore, more poverty in different coloured bars in one region, which vary depending on the number of children, again corresponds to the long-coloured bar.

For example, in the overall measurement of Turkey; based on the findings shown in Figure 2, it is seen that in a family consisting of mother and father with 1 child, the multidimensional poverty ratio is $6.8 \%$ in 2006 and this is represented by a blue bar. In the same year, in case the number of children in the household is 3 or more, the multidimensional poverty ratio reached $8.4 \%$ with an increase of more than 1.5 points, and this level was reflected in green. When the same scale was analysed for 2017 shown in Figure 2; it can be determined that households with 1 and 2 children have a poverty ratio of $4.4 \%$ (respectively blue and red bars), whereas households with 3 and more children have a poverty rate of $5.9 \%$ (green bar). Although the poverty ratio has declined in Turkey from 2006 to 2017, the findings suggest that the increase in the number of children in households in both 2006 and 2017 has negatively affected poverty.

When evaluated regionally, it can be said that the region with the highest poverty ratio among families with one child in 2006 was the Southeastern Anatolia Region with a rate of $11.4 \%$. On the other hand, it is

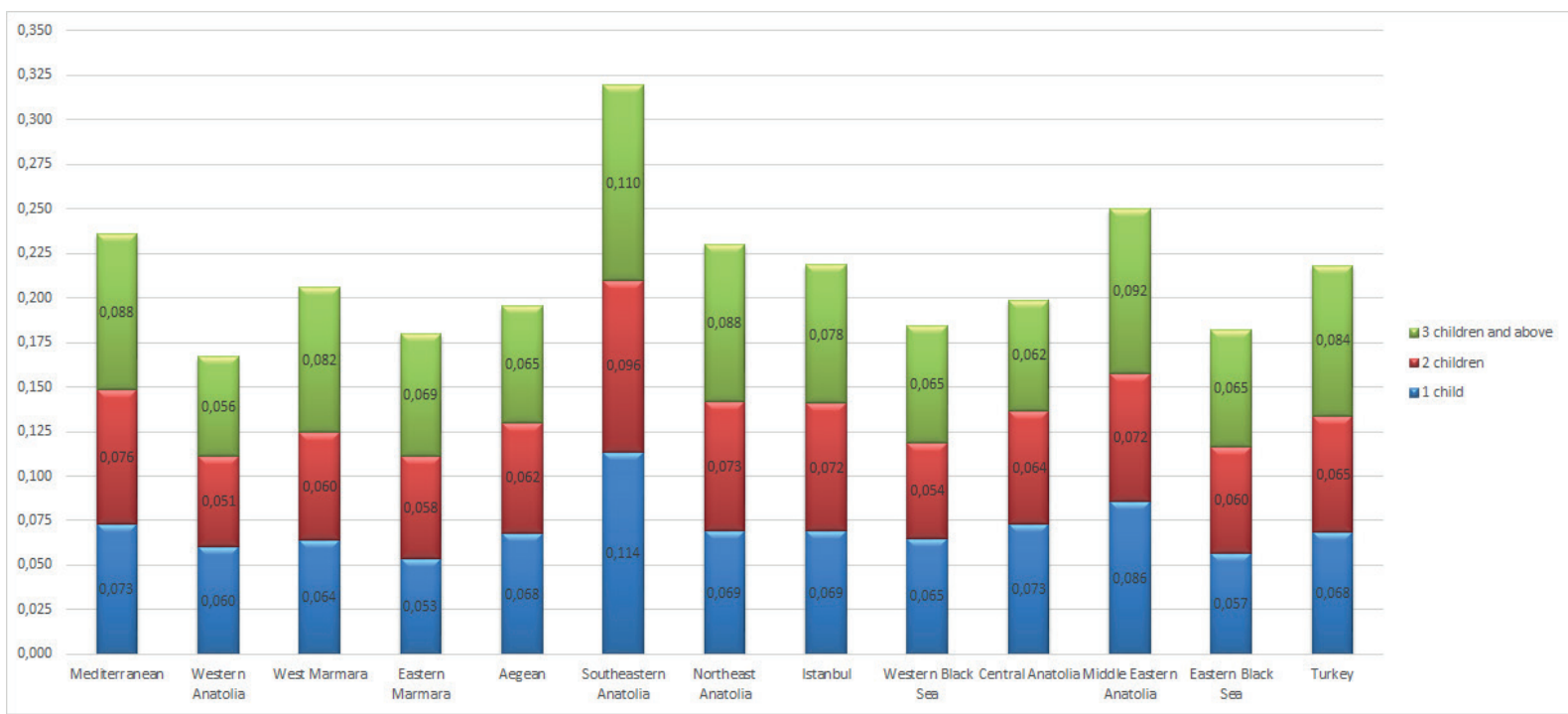

Figure 2: Multidimensional Poverty Ratios $\left(M_{0}\right)$ of Households Differing by Number of Children in Turkey and Level-1 Regions (2006) 
observed that households with 1 child in the same year with the lowest poverty ratio are located in East Marmara with a rate of 5.3\%. The poverty ratio in East Marmara has declined to $4.3 \%$ with the number of children reaching 3 or more, while this rate in Southeastern Anatolia remained at $11 \%$. In addition to the Southeastern Anatolia Region, other regions with relatively high poverty ratios in single-child households for 2006 can be listed as Middle Eastern Anatolia (8.6\%), Mediterranean (7.3\%) and Central Anatolia (7.3\%). The poverty ratio of Middle Eastern Anatolia has increased with the increase in the number of children and reached $9.2 \%$ and $8.8 \%$, respectively. On the other hand, the poverty ratio of households with one child has declined to $6.2 \%$ from $7.3 \%$ in Central Anatolia.

The seven regions, whose poverty ratios increased as the number of children increased to 3 and above from one child, are Northeast Anatolia (+1.9), West Marmara (+1.8), East Marmara (+1.6), Mediterranean (+1.5), Istanbul (+0.9), Eastern Black Sea $(+0.8)$ and Middle Eastern Anatolia (+0.6), respectively. In the Western Black Sea Region, there is no difference between the poverty ratios of households with one child and those with 3 or more children in 2006. The Central Anatolia Region is one of the regions where the poverty rate has decreased the most despite the increase in the number of children (from $7.3 \%$ to $6.2 \%$ ). In addition, it can be said that the increase in the number of children in the Southeastern Anatolia and Aegean Regions, albeit less than 5 per thousand, is positively reflected in household poverty.

When the multidimensional poverty measurements of 2017 are evaluated regionally, it is seen that the Southeastern Anatolia Region stands out again in all samples differing by the number of children (Figure 3). In other words, while the multidimensional poverty ratio of households with 1 child is $6.4 \%$ in this region, it is $6.6 \%$ in households with 2 children, and $7.3 \%$ in households with 3 or more children, respectively. Considering the sample groups of all three levels discussed, it can be said that the Southeastern Anatolia Region is disadvantaged compared to all other regions. The Central Anatolia and Northeast Anatolia Regions are also at the forefront in terms of high poverty ratios in all analysis groups. The regions with the lowest poverty ratio, especially in households with 3 and more children, are the Western Anatolia and Western Black Sea Regions with a rate of $4.2 \%$. In the same analysis, the East and West Marmara and Central Anatolia Regions are among the regions where poverty is relatively low. Based on these results, it can be suggested that poverty increases as we go from west to east, and this finding clarifies one of the questions in the study.

The fact that the number of children is 1,2 , and 3 or more might cause the differentiation of poverty between the regions. In other words, for example, the poverty of households with 1 child and 3 or more children in

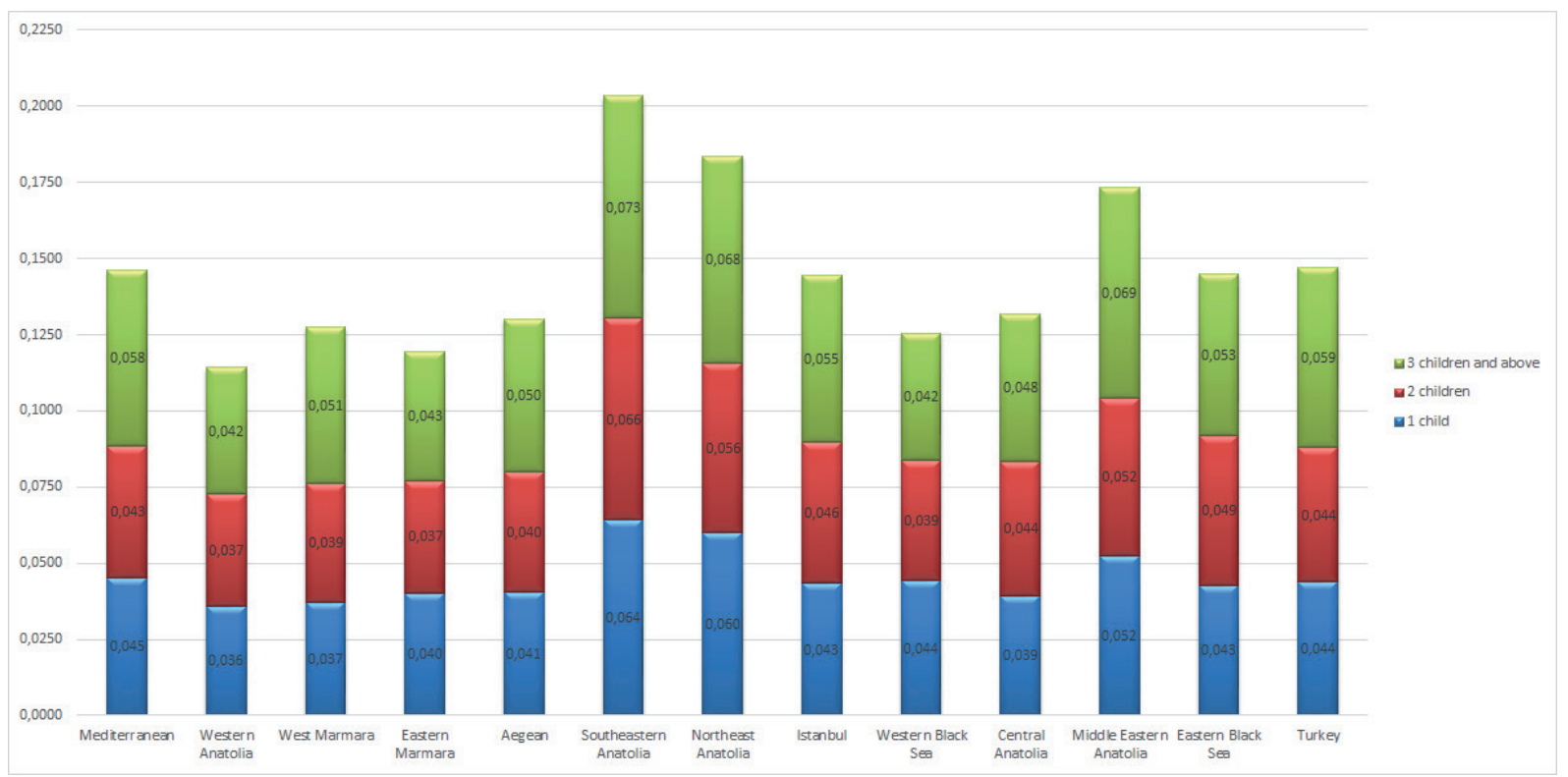

Figure 3: Multidimensional Poverty Ratios $\left(M_{0}\right)$ of Households by the Differences in the Number of Children in Turkey and Level-1 Regions (2017) 
the Middle Eastern Anatolia Region is increased by 1.7 points. The other regions where poverty is driven by a rising momentum with the increase in the number of children are West Marmara with an increase of 1.4 points, Mediterranean with 1.3 points and Istanbul with 1.2 points, respectively. Similarly, in 2017, the increase in the number of children in all regions except the Western Black Sea Region negatively affects and increases poverty. A decrease of 0.2 points is observed in the Western Black Sea Region.

As mentioned earlier, the number of households with one child is 1366, 1652 with two children, and 1398 with three or more children for the year of 2006. The number of those who were found to experience poverty in these households is 708,907 , and 551 , respectively. In other words, 551 of 1398 households with 3 or more children are poor according to the multidimensional poverty approach. On the other hand, the number of households with one child is 2907, 3237 with two children, and 2203 with three or more children for 2017. The number of poor households are 2218, 2484 , and 1365 by the number of children.

Figure 4 and Figure 5 were created to determine how the samples detailed regionally in Table 1 differ from each other according to the number of children identified as poor. These two figures show how the poor are regionally distributed according to the number of children. In this doughnut chart consisting of three layers, the inner layer reflects the share of poor households with 1 child, the middle layer with 2 children, and the outer layer with 3 or more children. In these figures, in which each region is represented by a different colour, it can be observed how the population of households, which increases from inside to outside according to the number of children, affects the share of the poor households in the region. For example, as shown in Figure $4,16.5 \%$ of the poor households with one child across Turkey are located in the Aegean Region and this region takes the first place in this ranking. Similarly, in 2006, $14.97 \%$ of the households identified as poor with only one child are in the Istanbul Region, followed by the Mediterranean Region with a ratio of $12.43 \%$. On the other hand, the lowest shares of poor households with 1 child belong to Southeastern Anatolia (1.13\%) and Middle Eastern (2.12\%) (inner layer of the graph). In the same year, $14.77 \%$ of 907 poor households with 2 children in Turkey are also located in the Aegean Region. The Regions of Western Anatolia (13.67\%) and Istanbul (11.03\%) also have a significant share of poor sample with 2 children (middle layer of the graph). As mentioned earlier, the poverty ratio is increased with the increase in the number of children, and this increase was found to be relatively high in the eastern regions. Out of 1398 households with three or more children, the majority of 551 poor households are located in the Central Anatolia and eastern regions. For example, 72 (13.07\%) poor households with 3 or more children are located in Southeastern Anatolia, and 60 (11.25\%) poor households are located in Cent-

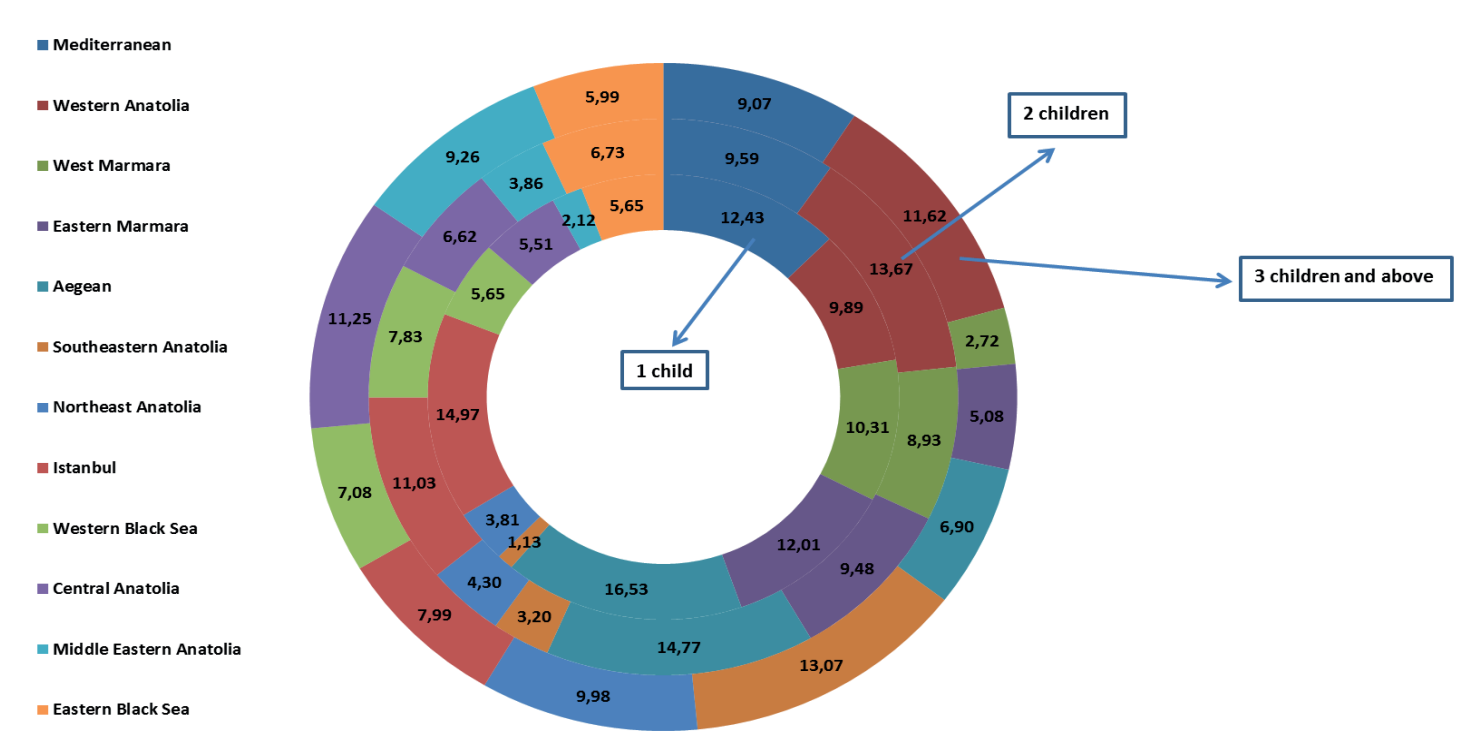

Figure 4: Regional Distribution of Poor Households (2006) 
ral Anatolia. In this sample group, which can also be described as a crowded family, only $2.72 \%$ of the poor households are located in West Marmara and 5.08\% in East Marmara, respectively (the outer layer of the graph). These findings, which reflect the year 2006, support the argument that poverty increases as the number of children increases and as we move from west to east of Turkey.

Similar results on the regional share of poor households are also encountered when the findings of 2017 shown in Figure 5 are considered. A significant portion (15.37\%) of the poor households (2218) with one child are in the Aegean Region. In other respects, it can be said that approximately 15 of every 100 households with 1 child in the total sample and identified as poor are located in the Aegean Region. East Marmara (11.99\%), Mediterranean (11.81\%) and Western Anatolia (11.68\%) show the regional distribution of the poor households with one child. Even these results indicate that the West is densely populated with poor households with fewer children (inner layer of the graph). In addition, the Aegean and Mediterranean Regions stand out with a share of $14.41 \%$ and $13.53 \%$, respectively, in the classification of poor households with 2 children (middle layer of the graph).

The main focus of this study is the sample group that consists of households with 3 or more children (2203), and as a result of the analysis, it was found that 1365 of these households were poor in 2017. Approximately
20\% (275) of these 1365 poor households are located in the Southeastern Anatolia Region. In other words, 1 in every 5 poor households with 3 or more children is located in the Southeastern Anatolia. This ratio can be considered quite high in a sample group including other regions as well. The Mediterranean Region is also at the top of the list with a share of $13.41 \%$. Nevertheless, it can be emphasized that West Marmara (2.34\%) and Eastern Black Sea (2.64\%) are the regions with the lowest share in the poor households. At first, the share of the Eastern Black Sea Region may seem surprising, but the fact that the number of households with 3 or more children in the 2017 sample of this region is 53 and 36 of these households are poor, actually supports the prediction that poverty will increase as we go to east from west. In the graph given in Figure 5, the limited number of samples can be considered among the reasons why the share of poor households with 3 or more children in the Eastern Black Sea Region is low. In summary, as $2.5 \%$ of 2203 households with 3 or more children in 2017 are located in the Eastern Black Sea Region, the low share of this region in the total poor can be considered usual and consistent (outer layer of the graph).

Another analysis of how households' poverty changes according to the diversity of the number of children is aimed at the deviations of regional poverties as reflected in Figure 6 and 7 from the averages in Turkey. While the multidimensional poverty ratio of some

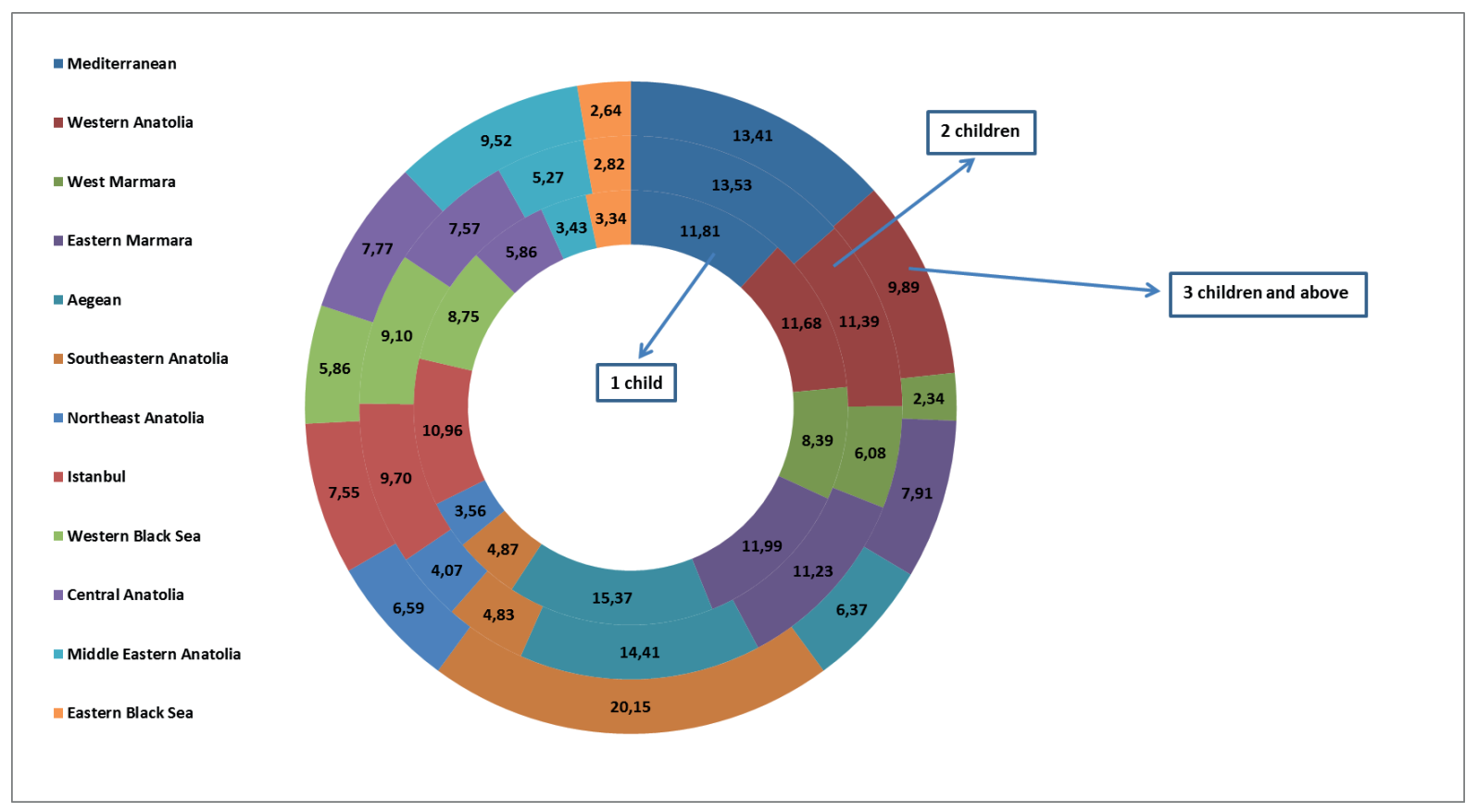

Figure 5: Regional Distribution of Poor Households (2017) 
regions based on both the number of children and the year remained behind the poverty rate of Turkey, it is in the opposite direction in some regions. At this point, it can be emphasized that while the area in the graph containing positive values above zero refers to the regions experiencing poverty above the Turkish average, the area containing negative values below zero refers to the regions in a better position than the country's average in terms of poverty.

Considering the data of 2006 (Figure 6), which is taken as the first period of the analysis, it can be said that the poverty rates of the Southeastern Anatolia, Northeast Anatolia, Middle Eastern Anatolia, Mediterranean Regions are above the Turkey's average in terms of child poverty in all sample groups. Especially the Southeastern Anatolia Region differs significantly in a negative way in all groups, the poverty rate of this region is 2.5 to 4.5 points above the average. As the number of children increases in these regions, the poverty of households approaches the averages of Turkey. In Istanbul and Central Anatolia Regions, the situation of being below or above the average differs according to the number of children. On the other hand, the poverty of households in all other regions remained behind the national average in all sample groups differing by the number of children. Considering the multidimensional poverty ratios of households with three or more children, especially in the Western Ana- tolia region, they are observed to be well behind the average in Turkey. Similar results are observed in the Aegean, Eastern Marmara, Western Black Sea, Central Anatolia and Eastern Black Sea Regions in households with three or more children. When we look at Istanbul for the same sample group, poverty was encountered below the average in Turkey, but the degree of this was relatively low.

Considering the deviation of the poverty values of the regions from the country averages for 2017 , the negative course of the Southeastern Anatolia Region in all child groups stands out (Figure 7). The deviation of this region from the average of Turkey, especially in terms of households with two or more children, was found to be above $2 \%$. At this point, it can be emphasized that almost all of the regions with poor households above the average poverty of Turkey are located in the east. From this point of view, it can be said that poverty is experienced above the country averages in the households of all sample groups in the Northeast Anatolia and Middle Eastern Anatolia Regions. It can also be stated that the poverty of households with one child in the Mediterranean and Western Black Sea Regions and with two children in Istanbul and Eastern Black Sea Regions exceeds the country average.

On the other hand, the poverty ratios of households in all groups of children in the Western Anatolia, East Marmara, West Marmara and Aegean Regions are lower

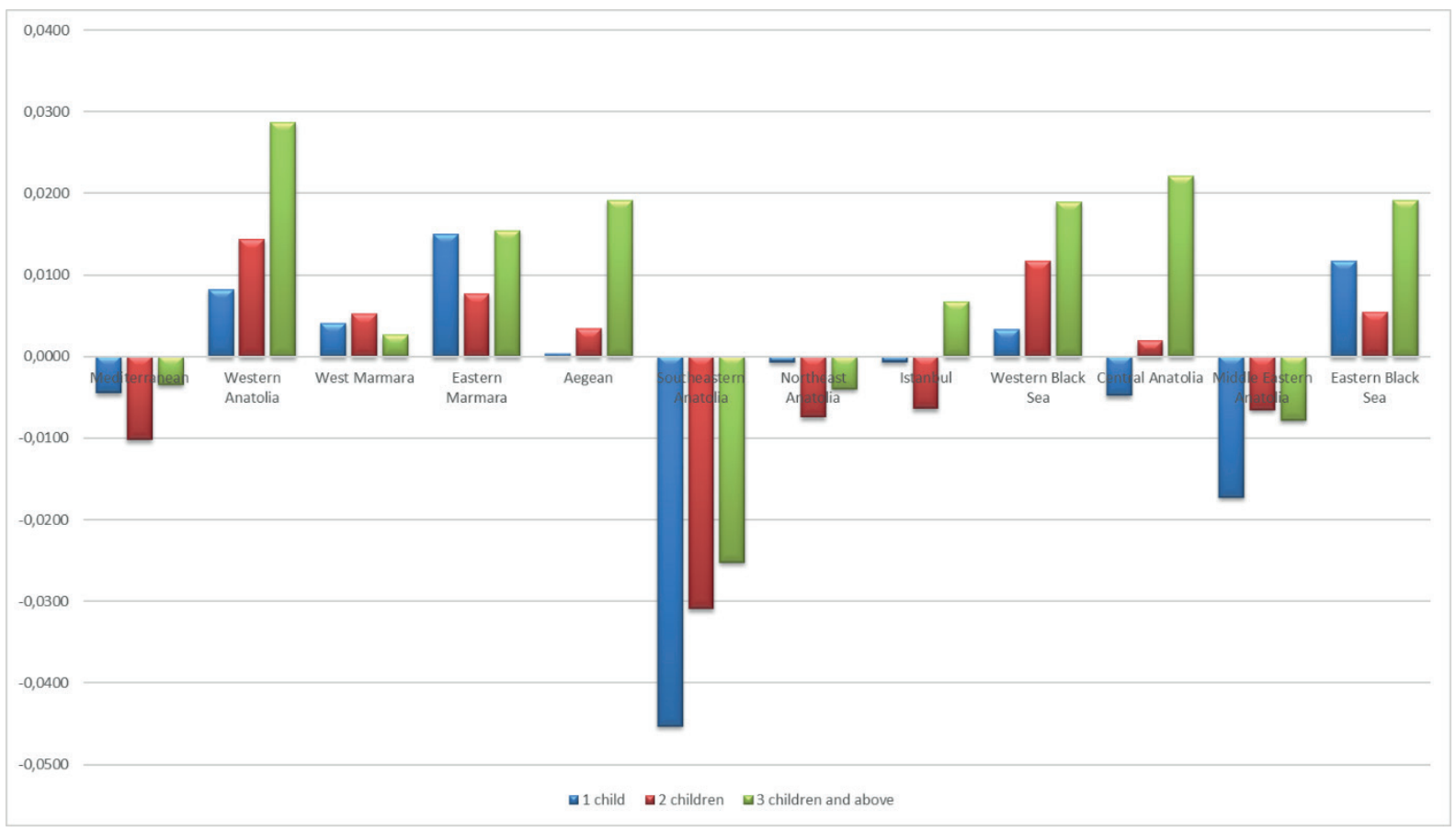

Figure 6: The Deviations of Regions from the Average Poverty Ratio of Turkey (2006) 


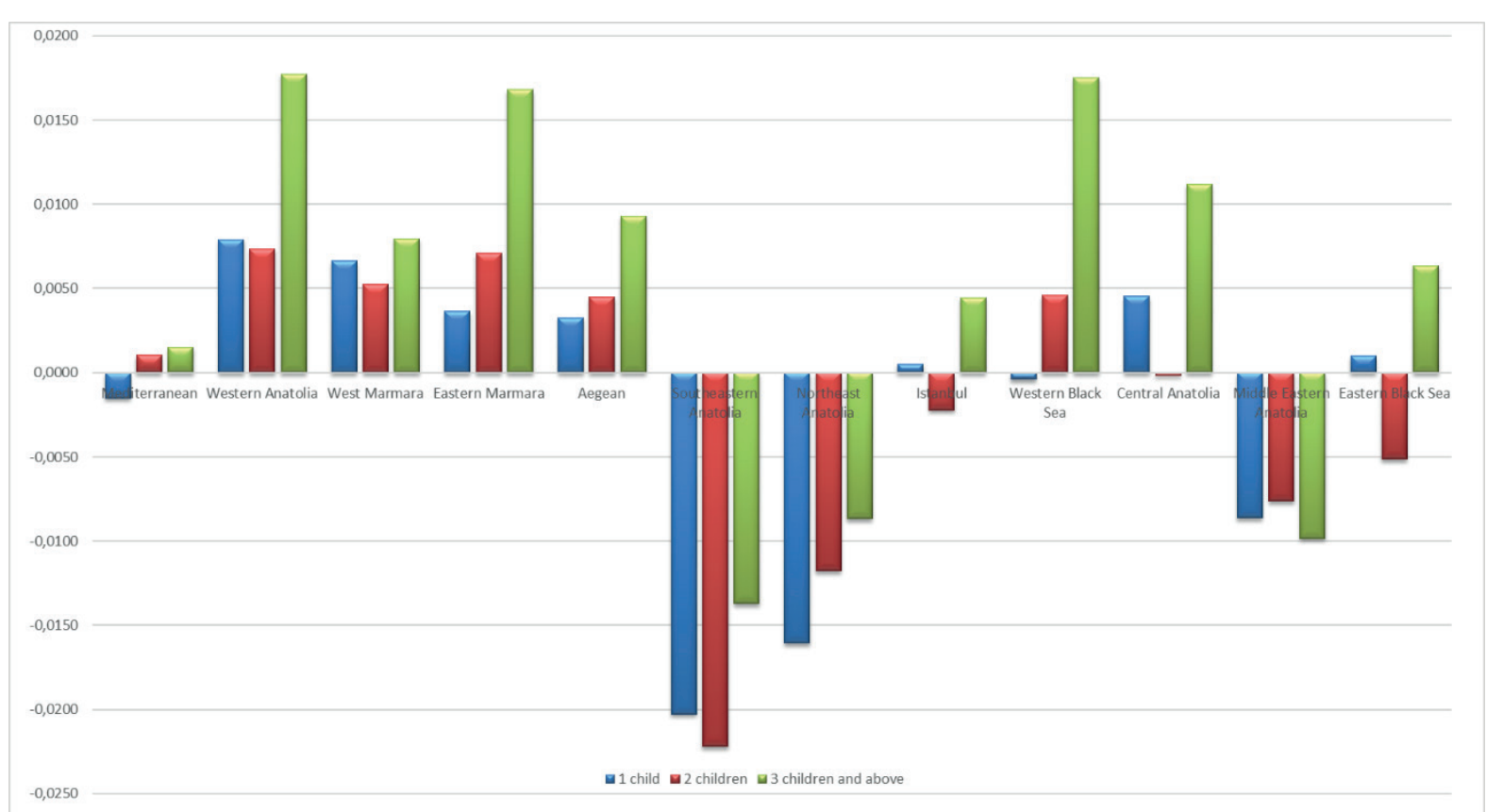

Figure 7: The Deviations of Regions from the Average Poverty Ratio of Turkey (2017)

compared to the averages of Turkey. In addition, the multidimensional poverty of households with 3 or more children in the Mediterranean, Istanbul, Western Black Sea, Central Anatolia and Eastern Black Sea Regions was found to be below the country average. Based on these results, the poverty rates are exceeding the average of
Turkey as we go to east from west, and the opposite is encountered as we go to west from east.

Another question that is sought to be answered in this study is about how poverty has changed in all groups of children nationally and regionally from 2006 to 2017. In Figure 8, which was created to reflect

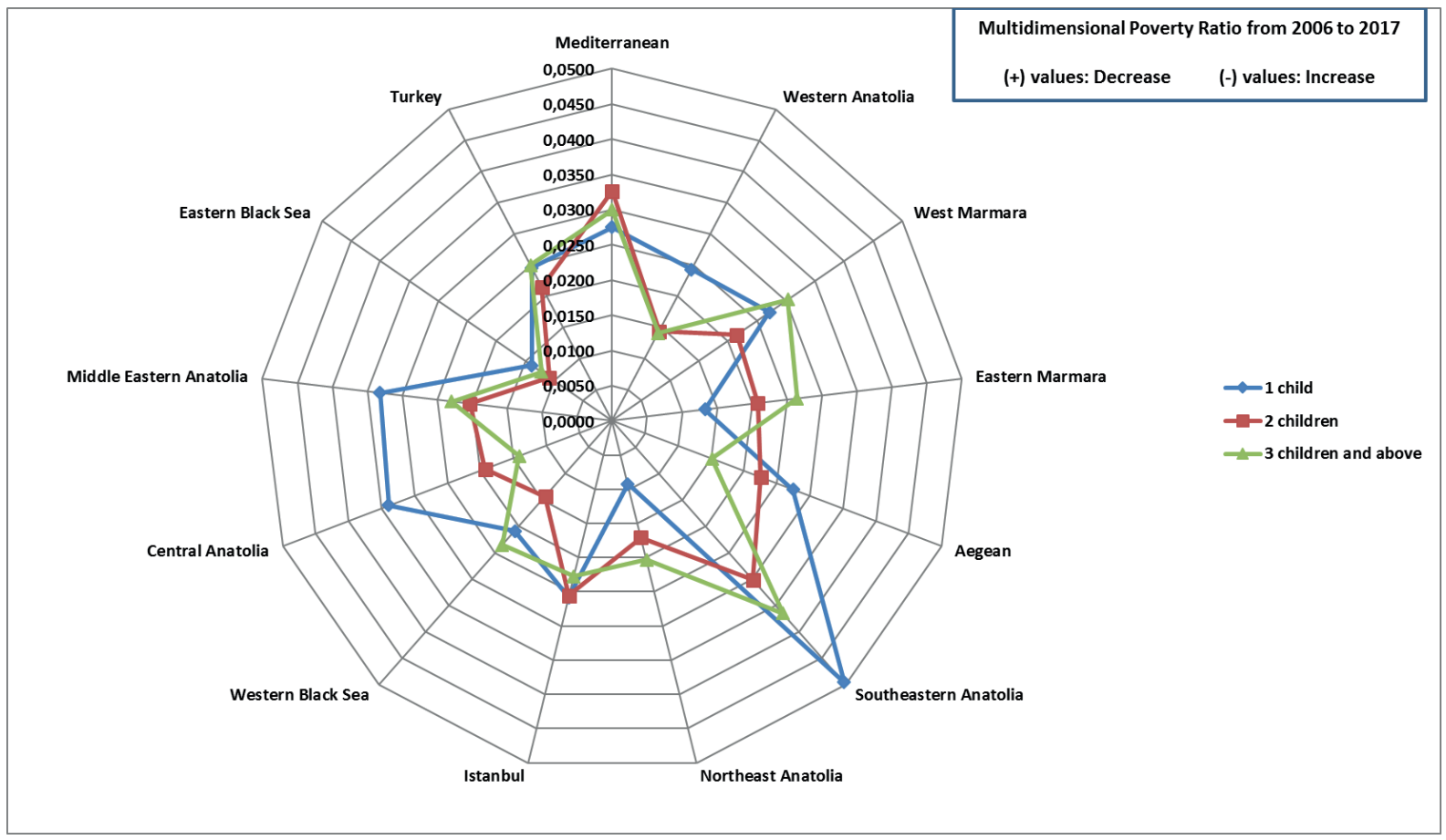

Figure 8: The Change of Multidimensional Poverty from 2006 to 2017 in Turkey and Level-1 Regions 
the change in question, positive values indicate that poverty is declined between periods, whereas negative values indicate that poverty in the relevant region is increased.

As shown in Figure 8, the poverty ratio has declined from 2006 to 2017 in Turkey, all regions and household groups differentiated by the number of children. In other words, the ratio of multidimensional poverty has declined in all analysis units, including the country in general, and this rate was declined by over 3\% especially in the Southeastern Anatolia region. In addition, the poverty ratio of households with 1 child in the Middle Eastern and Central Anatolia Regions and with 2 children in the Mediterranean Region has also declined over the past eleven years. The poverty rate decrease in other analysis units is in the range of $0.05 \%-2.5 \%$.

In other words, both 2006 and 2017 measurements show that the households with the most multidimensional poverty are those with 3 and more children. It can also be said that as we move from western parts of Turkey to the east, poverty has increased with the increase in the number of children. Finally, the multidimensional poverty ratio across Turkey declines slightly from 2006 to 2017 in accordance with the poverty measurements conducted by the TurkStat (2020) and the World Bank (2020) using the monetary indicators.

\section{CONCLUSION}

The aim of this study is to measure the poverty of households that differ according to the number of children aged 15 and under using the multidimensional measurement method. In determining the dimensions, indicators and weights required to calculate the multidimensional poverty of households, the study of Alkire et al. (2014) was taken as the basis. In their study, Alkire et al. (2014) created four dimensions in which Europe 2020, education, health and environmental factors are evaluated together for poverty measurement. These four dimensions are included in the study with twelve indicators. The Europe 2020 dimension is represented by "income", "work intensity" and "extreme material deprivation" sub-indicators, while the education dimension is represented by "graduated school", the health dimension is represented by "health status", "chronic health problem", "limitation in the activities" and "being unable to apply to the doctor". Finally, the environmental factors dimension is included in the study with sub-indicators of "housing ", "noise pollution", "environmental pollution" and "crime".
The study is conducted with the expectation that the poverty of households with one, two, three or more children will differ according to the number of children and the multidimensional poverty of households will increase with an increase in the number of children. It is also among the pre-analysis predictions that poverty will change in parallel with the increase in the number of children as we move from west to east.

The findings suggest that the increase in the number of children in households in both 2006 and 2017 has negatively affected poverty. Both the 2006 and 2017 findings show that multidimensional poverty is increasing as the number of children increases and as we go to east from west. It is seen that the multidimensional poverty rate was relatively lower in 2017. Another important finding obtained in this study is that the Southeast Anatolia, Northeast Anatolia, Middle Eastern Anatolia Regions experience poverty above the average of Turkey in all sample groups.

Saying these, this study has not directly searched the causality between poverty and increasing number of children. The required panel data for measuring the mentioned causality is not available. In addition, information on the level and quality of the education of the children and on their employment and income conditions is not available. Therefore the positive relationship between poverty and number of children is rather a co-change.

The Southeast Anatolia, Central Anatolia and Northeast Anatolia regions stand out in the deprivations experienced in all the indicators discussed in the measurement of poverty. From this point of view, policies aimed at eliminating excessive financial deprivation particularly in these regions (but in all actually) would have positive impacts on reducing household poverty. The measures taken by the government institutions and policies should not be limited to income but should also include education, health and environmental factors, so that improvements covering a wide perspective from education to health, from the physical structure of the house to the possibility of experiencing crime will strengthen individuals and prevent the poverty to become chronic. Improving the level of access to education and health opportunities in these regions will help reduce poverty in the long run. Average number of children in the above mentioned regions are higher compared to nation's average, therefore people's attention might drawn to the relationship between poverty and househol size as well. Finally, implementations regarding ensuring security and minimizing crime 
incidents, primarily in these regions, will help reduce regional poverty.

Considering that the children under the age of 15 will be included in the labor market in the future, the socio-economic structure of these households in the near future depends on the education of today's children and their possibility of finding a job in the future. In other words, the question is; with the increasing number of children, will the poverty of the household decrease with these children being included in the labor market and being employed? Or household population increase, results in unemployment and poverty given the economic conditions in Turkey, current level of unemployment and the experienced middle-income trap. Therefore, increase of the number of children in households without the improvements to the current conditions in Turkey to take young people's education and employment of more, it would reflect negatively on the poverty of households in the coming period. 15 years of age constitute $23 \%$ of the total population in Turkey. Especially in the eastern region of Turkey average median age (32.4 years) of being behind in the household it is associated with the relatively large number of children and young people. Therefore, the individuals in this group to bring income and contribute to their households in the future, of course, depend on their education level. The fact that 1 out of every 3 young people is neither educated nor employed today indicates the steps to be taken in this direction. Today, nearly half of the unemployed in Turkey for at least 6 months, is looking for work for at least 1 year is one in four. One way to reverse these periods is to improve educational opportunities, and another way is to create new jobs supported by technology. Otherwise, there does not seem to be a way to raise an income level caught in the middle-income trap and hence help households escape poverty. 


\section{REFERENCES}

Alkire, S. \& Santos, M, E., (2010). Acute multidimensional poverty: A new index for developing countries, United Nations Development Programme Human Development Reports Research Paper 2010/11.

Alkire, S. \& Foster, J., (2011a). Counting and multidimensional poverty measurement, Journal of Public Economics, 95(7), 476-487.

Alkire, S. \& Foster, J., (2011b). Understandings and misunderstandings of multidimensional poverty measurement, The Journal of Economic Inequality, 9(2), 289-314.

Alkire, S., Apablaza, M., \& Jung, E., (2014). Multidimensional poverty measurement for EU-SILC countries, Oxford Poverty and Human Development Initiative Working Paper Series, 36b, 1-49.

Alkire, S. \& Jahan, S., (2018). The new global MPI 2018: Aligning with the sustainable development goals, Oxford Poverty and Human Development Initiative Working Paper Series, 121, 1-21.

Alkire, S., (2018). The research agenda on multidimensional poverty measurement: Important and as-yet unanswered questions, Oxford Poverty and Human Development Initiative Working Paper Series, 119, 1-24.

Anand, S., (1977). Aspects of poverty in Malaysia. Review of Income and Wealth, 23(1), 1-16.

Anyanwu, J. C., (2005). Rural poverty in Nigeria: Profile, determinants and exit paths. African Development Review, 17(3), 435-460.

Anyanwu, J. C., (2014). Marital status, household size and poverty in Nigeria: Evidence from the 2009/2010 survey data. African Development Review, 26(1), 118-137.

Batana, Y. M., (2013). Multidimensional measurement of poverty among women in Sub-Saharan Africa, Social Indicators Research, 111(2), 337-362.

Bourguignon, F. \& Chakravarty, S.R., (2003). The Measurement of multidimensional poverty, Journal of Economic Inequality, 1(1), 25-49.

Foster, J., Greer, J., \& Thorbecke, E., (1984). A class of decomposable poverty measures, Econometrica, 52(3), 761-766.

European Commission, (2010). A Strategy for smart, sustainable and inclusive growth. https://ec.europa.eu/eu2020/ pdf/COMPLET\%20EN\%20BARROSO\%20\%20\%20007\%20 -\%20Europe\%202020\%20-\%20EN\%20version.pdf, (20.06.2019).

Geda, A., De Jong, N., Mwabu, G. \& Kimenyi, M., (2001). Determinants of poverty in Kenya: A household level analysis. ISS Working Paper Series/General Series, 347, 1-20.
Haughton, J. \& Khandker, S.R., (2009). Handbook on Poverty and Inequality, The World Bank, Washington.

Khan, R. E. A., Rehman, H. \& Abrar ul Haq, M., (2015). Determinants of rural household poverty: the role of household socioeconomic empowerment. American-Eurasian J. Agric. \&Environ. Sci, 15(1), 93-98.

Lanjouw, P. \& Ravallion, M., (1995). Poverty and household size. The Economic Journal, 105(433), 1415-1434.

Lugo, A.M. \& Maasoumi, E., (2009). Multidimensional Poverty Measures from an Information Theory Perspective, Oxford Poverty and Human Development Initiative Working Paper Series, 10, Oxford.

Meyer, D. F. \& Nishimwe-Niyimbanira, R., (2016). The impact of household size on poverty: An analysis of various low-income townships in the Northern Free State region, South Africa. African population studies, 30(2).

Sen, A., (1976). Poverty: An ordinal approach to measurement, Econometrica, 44(2), 219-231.

Sen, A., (1983). Poor, Relatively Speaking, Oxford Economic Papers, 35(2), 153-169.

Sen, A., (1997). On Ethics in Economics, Basil Blackwell, Oxford.

Sen, A., (1999). Development As Freedom, NY: Knopf Publishers, New York.

Sen, A., (2004). Capabilities, Lists, and Public Reason: Continuning the Conversation, Feminst Economics, 10(3), 77-80.

Seth, S. \& McGillivay, M., (2018). Composite indices, alternative weights and comparison robustness, Social Choice and Welfare, 51, 657-679.

Song, S. \& Imai, K., (2018). Does the hunger safety net programme reduce multidimensional poverty? Evidence from Kenya, Oxford Poverty and Human Development Initiative Working Paper Series, 124, 1-26.

TurkStat, (2017). Türkiye İstatistik Kurumu Gelir ve Yaşam Koşulları Araştırması, Ankara.

TurkStat, (2020). Temel İstatistikler, Gelir, Yaşam, Tüketim ve Yoksulluk, http://www.tuik.gov.tr/UstMenu.do?metod=temelist, (04.08.2020).

World Bank, (2020). World Bank Data, Poverty Data, https:// data.worldbank.org/topic/poverty, (04.08.2020).

Zanbak, M., (2014). Yetenekler Yaklaşımı Perspektifi Ile YoksulIuğun Ölçülmesi: Yoksulluğun Kayıp Boyutları Üzerine Ampirik Bir Uygulama, Akdeniz Üniversitesi Sosyal Bilimler Enstitüsü, Yayınlanmamış Doktora Tezi, Antalya.

Zanbak, M. \& Çağatay, S., (2013). Yetenek yaklaşımı temelinde yoksulluğun ölçülmesi: Mersin ve Erzurum illerinde yoksulluğun kayıp boyutları. iktisat Işletme ve Finans, 28(327), 67-104. 


\section{Endnotes}

${ }^{1}$ In this study, the dimensions and indicators that Alkire and Foster (2011a, 2011b) and Alkire and Jahan (2018) addressed in their studies were not used, but the dimensions, indicators, deprivation conditions and weights, which are shown in Table 2, presented in the study of Alkire et al. (2014) were used.

${ }^{2}$ At this point, it can be emphasized again that the households were represented by the data of the "household head" based on their verbal statements. 